\section{6 OPEN ACCESS}

\title{
Comparison of tocilizumab monotherapy versus methotrexate monotherapy in patients with moderate to severe rheumatoid arthritis: the AMBITION study
}

\author{
G Jones, ${ }^{1}$ A Sebba, ${ }^{2} \mathrm{~J} \mathrm{Gu},{ }^{3}$ M B Lowenstein, ${ }^{4}$ A Calvo, ${ }^{5} \mathrm{~J} \mathrm{~J} \mathrm{Gomez-Reino,}{ }^{6}$ D A Siri, \\ M Tomšic ${ }^{8}{ }^{8}$ E Alecock, ${ }^{9}$ T Woodworth, ${ }^{9}$ M C Genovese ${ }^{10}$
}

\begin{abstract}
${ }^{1}$ Menzies Research Institute, University of Tasmania, Hobart, Australia; ${ }^{2}$ Arthritis Research of Florida, Palm Harbor, Florida, USA; ${ }^{3}$ Department of Rheumatology, Third Affiliated Hospital of Sun Yat-sen University, Guangzhou, China;

${ }^{4}$ The Arthritis Center, Palm Harbor, Florida, USA; ${ }^{5}$ San Felipe Clinic, Lima, Peru;

${ }^{6}$ University of Santiago de Compostela, Santiago de Compostela, Spain; ${ }^{7} \mathrm{CAICl}$ Institute, Rosario, Argentina;

${ }^{8}$ Department of Rheumatology, University Medical Centre, Ljubljana, Slovenia; ${ }^{9}$ Roche Products Ltd, Welwyn, UK; ${ }^{10}$ Division of Immunology and Rheumatology, Stanford University Medical Center, Palo Alto, California, USA
\end{abstract}

Correspondence to: Professor G Jones, Menzies Research Institute, University of Tasmania, Hobart, TAS 7001, Australia; g.jones@utas.edu.au

Accepted 19 February 2009 Published Online First

17 March 2009

\section{ABSTRACT}

Background: The anti-interleukin (IL) 6 receptor antibody tocilizumab inhibits signalling of IL6, a key cytokine in rheumatoid arthritis (RA) pathogenesis.

Objective: To evaluate through the AMBITION study the efficacy and safety of tocilizumab monotherapy versus methotrexate in patients with active RA for whom previous treatment with methotrexate/biological agents had not failed.

Methods: This 24-week, double-blind, double-dummy, parallel-group study, randomised 673 patients to either tocilizumab $8 \mathrm{mg} / \mathrm{kg}$ every 4 weeks, or methotrexate, starting at $7.5 \mathrm{mg} /$ week and titrated to $20 \mathrm{mg} /$ week within 8 weeks, or placebo for 8 weeks followed by tocilizumab $8 \mathrm{mg} / \mathrm{kg}$. The primary end point was the proportion of patients achieving American College of Rheumatology (ACR) 20 response at week 24.

Results: The intention-to-treat analysis demonstrated that tocilizumab was better than methotrexate treatment with a higher ACR20 response (69.9 vs 52.5\%; $p<0.001$ ), and 28-joint Disease Activity Score (DAS28) $<2.6$ rate (33.6 vs $12.1 \%$ ) at week 24 . Mean high-sensitivity Creactive protein was within the normal range from week 12 with tocilizumab, whereas levels remained elevated with methotrexate. The incidence of serious adverse events with tocilizumab was $3.8 \%$ versus $2.8 \%$ with methotrexate $(p=0.50)$, and of serious infections, $1.4 \%$ versus $0.7 \%$, respectively. There was a higher incidence of reversible grade 3 neutropenia (3.1\% vs $0.4 \%$ ) and increased total cholesterol $\geqslant 240 \mathrm{mg} / \mathrm{dl}$ ( $13.2 \%$ vs $0.4 \%)$, and a lower incidence of alanine aminotransferase elevations $>3 \times-<5 \times$ upper limit of normal $(1.0 \%$ vs $2.5 \%)$, respectively.

Conclusion: Tocilizumab monotherapy is better than methotrexate monotherapy, with rapid improvement in RA signs and symptoms, and a favourable benefit-risk, in patients for whom treatment with methotrexate or biological agents has not previously failed.

Trial registration number: NCT00109408

Rheumatoid arthritis (RA) is a systemic inflammatory disease characterised by joint pain, stiffness and swelling due to synovial inflammation, as well as fatigue and limitations in physical function, and increased morbidity and mortality.

Interleukin 6 (IL6) is a pleiotropic proinflammatory cytokine produced by multiple cell types and involved in diverse physiological and pathological processes. ${ }^{2}{ }^{3}$ Raised serum and synovial fluid IL6 levels correlate with disease activity in patients with RA; thus, inhibition of IL6 represents a novel therapeutic approach to treatment. ${ }^{45}$
Tocilizumab is a humanised anti-IL6 receptor antibody that inhibits both soluble and membraneexpressed IL6 receptors (IL6R) limiting multiple IL6 proinflammatory activities through inhibition of the gp130 pathway. ${ }^{67}$ Tocilizumab has demonstrated efficacy in moderate to severe active RA with inadequate clinical response to disease-modifying antirheumatic drugs (DMARDs) or to tumour necrosis factor (TNF) inhibitors. ${ }^{8-13}$ Moreover, in a phase 3 study in Japan, more patients receiving tocilizumab $8 \mathrm{mg} / \mathrm{kg}$ monotherapy showed reduced radiographic progression than those receiving DMARDs. ${ }^{10}$ However, tocilizumab has not been studied in patients for whom DMARDs have not previously failed.

Methotrexate remains the most commonly used DMARD and is the recommended standard against which new DMARDs should be evaluated. ${ }^{14-16}$ To date, there is limited evidence that monotherapy with other treatments is better than methotrexate, as neither etanercept nor adalimumab monotherapy were statistically better than methotrexate in standard clinical efficacy parameters at 24 weeks in the ERA, TEMPO, and PREMIER trials. ${ }^{17-19}$ The objective of the AMBITION (Actemra versus Methotrexate double-Blind Investigative Trial In mONotherapy) study was to compare the efficacy and safety of tocilizumab monotherapy with that of methotrexate monotherapy in patients with active RA for whom treatment with methotrexate or biological agents had not previously failed.

\section{PATIENTS AND METHODS \\ Patients}

Patients were $\geqslant 18$ years, with moderate to severe $\mathrm{RA}$ for $\geqslant 3$ months. Active RA was defined by the presence of $\geqslant 6$ swollen joints (SJC) from a total of $66, \geqslant 8$ tender joints (TJC) from a total of 68 , and a C-reactive protein (CRP) level $\geqslant 1 \mathrm{mg} / \mathrm{dl}$ or erythrocyte sedimentation rate (ESR) $\geqslant 28 \mathrm{~mm} / \mathrm{h}$. Oral glucocorticoids (up to $10 \mathrm{mg} /$ day prednisone or equivalent) and non-steroidal anti-inflammatory drugs were permitted if the dose was stable for $\geqslant 6$ weeks. Patients were excluded if they had clinically unstable concurrent illnesses (and screened according to local standards and also excluded if they had active or untreated latent tuberculosis), had been unsuccessfully treated with an anti-TNF $\alpha$ agent, had received methotrexate in the 6 months preceding randomisation or discontinued previous methotrexate treatment because of clinically important adverse effects or lack of efficacy. Patients who had temporarily discontinued 


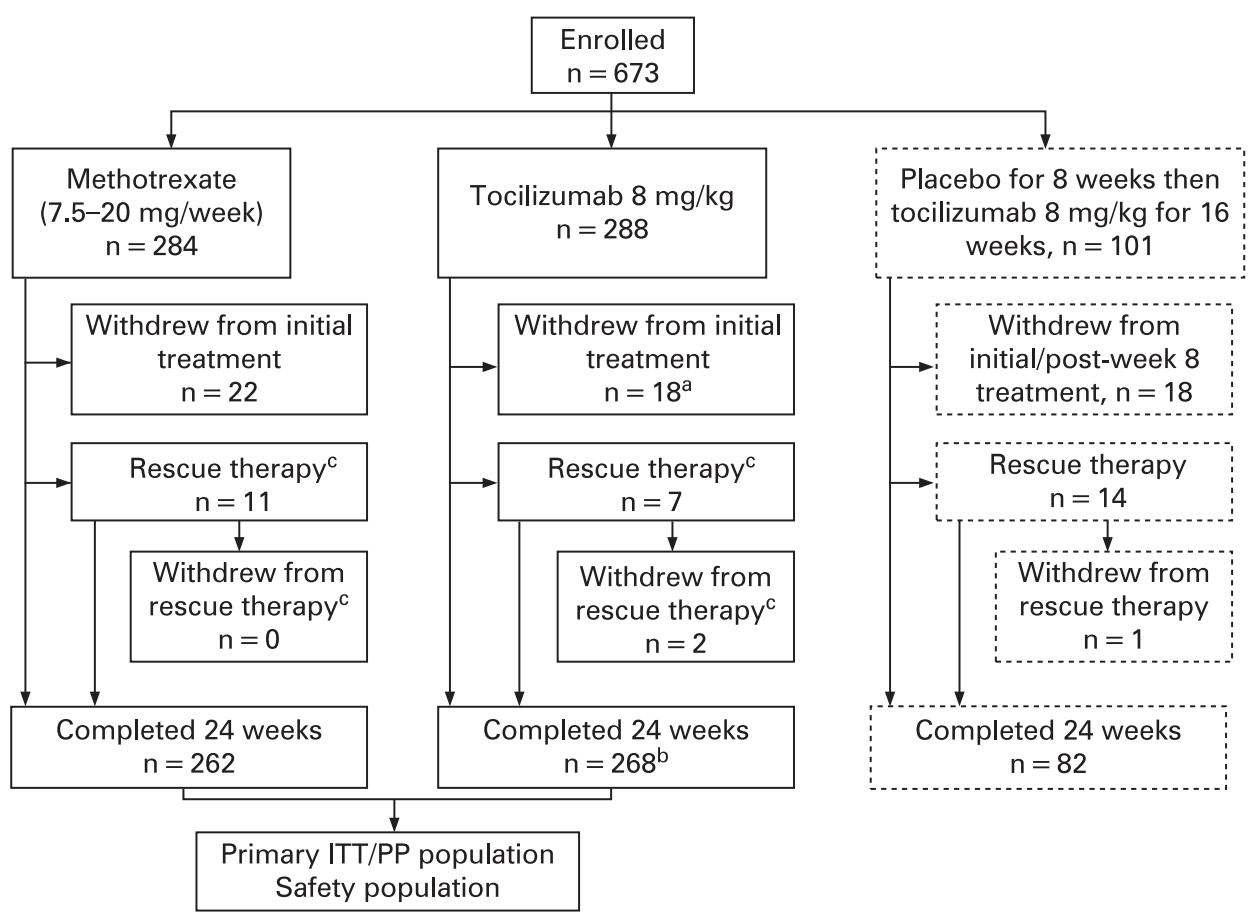

Figure 1 Study enrolment, randomisation and study completion. ancludes one patient who did not complete 24 weeks of treatment and therefore should have been counted as having withdrawn prematurely; bincludes one patient who missed the first dose of intravenous study drug, but received 24 weeks of the oral study drug and therefore should have been considered a completer; ' ${ }^{\circ}$ only patients enrolled in the placebo controlled substudy could receive rescue treatment with tocilizumab $8 \mathrm{mg} / \mathrm{kg}$ within the first 8 weeks of double-blind treatment; ITT, intention to treat; PP, per-protocol.

methotrexate treatment owing to side effects or wanted to become pregnant and those who discontinued anti-TNF $\alpha$ treatment for reasons other than efficacy (eg, treatment cost, side effects) could be included in the study.

\section{Study protocol}

Patients were randomised in a double-blind, double-dummy fashion to either tocilizumab $8 \mathrm{mg} / \mathrm{kg}$ intravenously every 4 weeks, or to methotrexate oral capsules, weekly (escalating dose regimen: initial dose $7.5 \mathrm{mg}$, increasing to $15 \mathrm{mg}$ at week 4 and to $20 \mathrm{mg}$ at week 8) together with folate ( $\geqslant 5 \mathrm{mg} /$ week). Methotrexate dose reduction to $10 \mathrm{mg}$ weekly was permitted for safety reasons.

Patients were assessed for efficacy and safety using a dual assessor approach to ensure blinded evaluation for efficacy; a trained joint assessor, with no access to patient data, performed each SJC and TJC.

To enable sensitivity testing for the non-inferiority claim, patients in the USA, Canada, and Israel were randomised (1:1:1) to the previously described two arms and an additional placebo arm as part of a substudy (fig 1). In the placebo arm patients received methotrexate placebo and tocilizumab placebo for 8 weeks (two infusions); from week 8 placebo infusion was replaced by tocilizumab $8 \mathrm{mg} / \mathrm{kg}$ infusion for the remaining 16 weeks of the study. Patients taking part in the placebocontrolled substudy who experienced $20 \%$ worsening from baseline in the SJC and TJC before week 8 could receive rescue treatment with tocilizumab $8 \mathrm{mg} / \mathrm{kg}$ at the investigator's discretion.

The protocol was approved by institutional review boards/ ethics committees, with written informed consent obtained from each patient before study participation. The study was conducted in full accordance with the principles of the
Declaration of Helsinki and with laws and regulations of countries in which the research was conducted.

\section{Study end points}

The primary end point was the proportion of patients with an ACR20 response at week $24 .{ }^{20}$ Secondary end points included the proportion of patients with ACR50/70 responses at week 24 , and the time to onset of ACR20/50/70 responses. Changes from baseline at week 24 in 28-joint count Disease Activity Score (DAS28; using ESR) were also evaluated. The proportion of patients in clinical remission (with DAS28 <2.6), with low disease activity (DAS28 $\leqslant 3.2$ ) and with EULAR good/moderate responses at week 24 were assessed. ${ }^{21} 22$ Improvement in physical function was assessed by change from baseline at week 24 in the Health Assessment Questionnaire-Disability Index (HAO-DI).

\section{Safety assessments}

Patients were monitored for adverse events (AEs), serious AEs, infections, withdrawals due to AEs, deaths and clinically significant changes in vital signs and laboratory tests.

\section{Statistical methodology}

The primary analysis group for the assessment of both efficacy and safety consisted of all patients randomised to either tocilizumab or methotrexate; patients initially randomised to placebo were assessed in subanalyses. The intention-to-treat (ITT) population included all randomised patients who received at least one infusion of the study treatment; depending on the purpose of analysis, ITT patients initially randomised to placebo were excluded. The per-protocol population (PP) included all patients in the ITT population who received more than twothirds of the study treatments and did not change concomitant 
Table 1 Patients demographics and baseline characteristics (PP and ITT populations)

\begin{tabular}{|c|c|c|c|c|}
\hline \multirow[b]{2}{*}{ Characteristics } & \multicolumn{2}{|c|}{ Tocilizumab 8 mg/kg } & \multicolumn{2}{|l|}{ Methotrexate } \\
\hline & $\begin{array}{l}P P \\
(n=265)\end{array}$ & $\begin{array}{l}\text { ITT } \\
(n=286)\end{array}$ & $\begin{array}{l}P P \\
(n=259)\end{array}$ & $\begin{array}{l}\text { ITT } \\
(n=284)\end{array}$ \\
\hline Age (years), mean (SD) & $51.1(13.1)$ & $50.7(13.1)$ & $50.1(12.8)$ & $50.0(12.9)$ \\
\hline \multicolumn{5}{|l|}{ Duration of disease, years } \\
\hline Mean (SD) & $6.4(7.7)$ & $6.4(7.9)$ & $6.3(7.9)$ & $6.2(7.8)$ \\
\hline Median (min-max) & $3.2(0.1-44.7)$ & $3.1(0.1-44.7)$ & $3.2(0.2-49.6)$ & $3.1(0.2-49.6)$ \\
\hline DAS28, mean (SD) & $6.8(1.0)$ & $6.8(1.0)$ & $6.8(0.9)$ & $6.8(0.9)$ \\
\hline Previous DMARDs/anti-TNF blockers (n), mean (SD) & $1.2(1.3)$ & $1.2(1.3)$ & $1.1(1.4)$ & $1.1(1.4)$ \\
\hline Methotrexate naïve, $\mathrm{n}(\%)$ & $176(66)$ & $191(67)$ & $171(66)$ & $190(67)$ \\
\hline Previous use of anti-TNFs, $\mathrm{n}(\%)^{*}$ & $24(8.3)$ & & $21(7.4)$ & \\
\hline Oral steroid use, $\mathrm{n}(\%)$ & $128(48)$ & $137(48)$ & $122(47)$ & $133(47)$ \\
\hline Haemoglobin value $<$ LLN, n (\%) & $101(38)$ & & $115(44)$ & \\
\hline HAQ-DI, mean (SD) & $1.6(0.7)$ & $1.6(0.7)$ & $1.5(0.6)$ & $1.5(0.6)$ \\
\hline Pain VAS 100 mm, mean (SD) & $59.2(22.5)$ & $58.7(22.9)$ & $61.3(20.4)$ & $61.5(20.6)$ \\
\hline Patient VAS 100 mm, mean (SD) & $64.0(21.5)$ & $63.9(21.9)$ & $65.4(19.5)$ & $65.6(19.8)$ \\
\hline Physician VAS 100 mm, mean (SD) & $63.2(15.7)$ & $63.0(16.1)$ & $63.2(16.3)$ & $63.6(16.7)$ \\
\hline
\end{tabular}

${ }^{*}$ Safety population (tocilizumab $8 \mathrm{mg} / \mathrm{kg}, \mathrm{n}=288$; methotrexate, $\mathrm{n}=284$ ).

CRP, C-reactive protein; DAS28, 28-joint Disease Activity Score; DMARDs, disease-modifying antirheumatic drugs; ESR, erythrocyte sedimentation rate; HAQ-DI, Health Assessment Questionnaire-Disability Index; ITT, intention to treat; LLN, lower limit of normal; PP, per-protocol; SD, standard deviation; SJC, swollen join count; TJC, tender joint count; TNF, tumour necrosis factor; VAS, visual analogue scale.

corticosteroids or non-steroidal anti-inflammatory drugs. The safety population included all randomised patients who received $\geqslant 1$ infusion and $\geqslant 1$ post-randomisation safety assessment.

The primary efficacy analysis was a non-inferiority comparison of tocilizumab with methotrexate using the PP population. The null hypothesis was that the proportion of patients with an ACR20 response in the tocilizumab treatment arm would be more than 12 percentage points lower than the proportion of patients in the methotrexate arm at week 24 . If non-inferiority was met, superiority of tocilizumab was to be tested using the primary analysis ITT population. ACR20 response rates were analysed using extended Mantel-Haenszel statistics, with adjustment stratification applied at randomisation (site and disease duration). A sample size of 275 patients per arm would provide at least $90 \%$ power to test the null hypothesis.

To support the primary endpoint result, the same analysis (using the ITT population) was performed at week 8 between the tocilizumab and placebo groups. A comparison of 100 placebo patients with 275 tocilizumab patients would provide a $>90 \%$ power to demonstrate tocilizumab superiority to placebo at week 8 .

For secondary end points, no non-inferiority limits were predefined; however, superiority was achieved if the lower limit of the $95 \%$ confidence interval (95\% CI) for treatment difference between tocilizumab and methotrexate was higher than 0 in the ITT population analysis. Changes from baseline in DAS28, CRP, haemoglobin and HAQ-DI at week 24 were compared between treatment groups using an analysis of covariance model. The proportion of patients with a DAS28 score $<2.6$ and EULAR response at week 24 were compared between treatment groups using logistic regression.

\section{RESULTS}

\section{Patient randomisation and baseline demographics}

A total of 673 patients were randomised into the study (fig 1). Most patients completed 24 weeks' treatment: 268 (93\%) patients in the tocilizumab group and 262 (92\%) patients in the methotrexate group. General demographic and baseline characteristics were well balanced (table 1). The majority of the patients were methotrexate-naïve ( $\sim 66 \%$ per arm) with a mean disease duration of 5 years; the mean number of previous DMARDs/anti-TNFs was 0.5 and only $40 \%$ had previously been treated with oral steroids. The mean weekly methotrexate dose over 24 weeks was $15.5 \mathrm{mg}$, with $73.5 \%$ of patients attaining $20 \mathrm{mg}$ weekly at week 8 .

\section{Clinical efficacy}

Improvement in signs and symptoms

After establishing non-inferiority in the PP population (ACR20 at week 24: $70.6 \%$ for tocilizumab versus $52.1 \%$ for methotrexate; weighted difference 0.21 (95\% CI 0.13 to 0.29$)$ ), tocilizumab was confirmed as superior to methotrexate (ITT), with a weighted difference for ACR20 response at week 24 of 0.19 (95\% CI 0.11 to $0.27, \mathrm{p}<0.001$; fig $2 \mathrm{~A}$ ). Furthermore, compared with the placebo control arm, tocilizumab was also superior at week 8 (ACR20: 55.6 vs 13.1\%, ITT) with a weighted difference of 0.43 (95\% CI 0.34 to 0.52 ). The superiority of tocilizumab was also present in an exploratory analysis of MTX-naive patients (ITT; fig 2B)

The proportion of ACR50 (44\%) and ACR70 (28\%) responders (ITT; fig 2A) at week 24 was also statistically superior for tocilizumab compared with methotrexate (weighted difference between treatments: 0.12 for ACR50 (95\% CI 0.04 to 0.20; $\mathrm{p}=0.002)$; and 0.14 for ACR70 (95\% CI 0.07 to $0.22 ; \mathrm{p}<0.001)$ ).

The ACR20 response rate with tocilizumab was statistically better than that of methotrexate as early as week 2 (ITT; 24.1 vs $10.2 \%$ ), with differences between the groups increasing over time. Compared with methotrexate, ACR50 and ACR70 responses were consistently observed in more tocilizumabtreated patients from week 4 and week 8 onwards (fig 2C). 

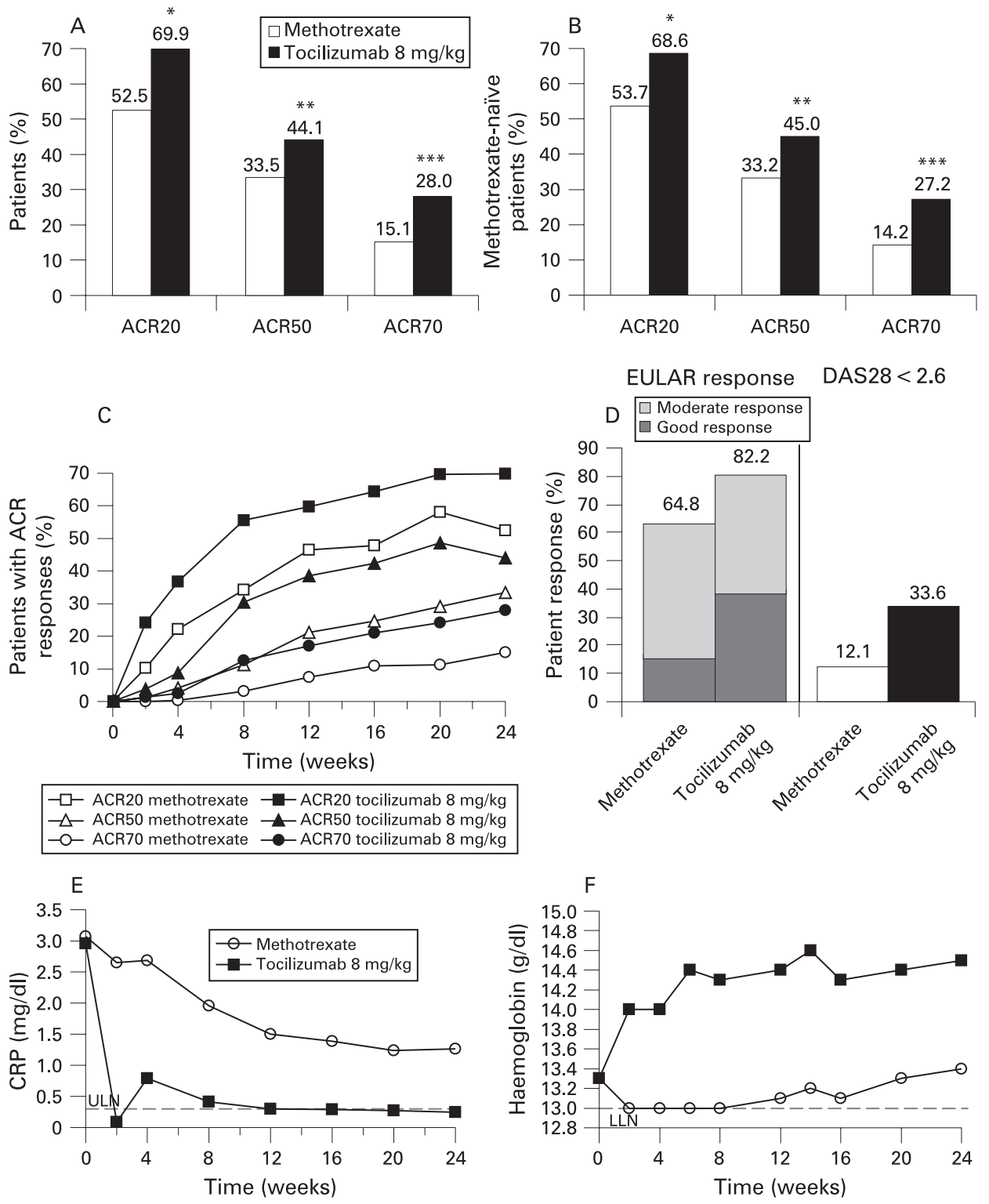

Figure 2 Improvement in signs and symptoms of disease. (A) Proportion of patients achieving ACR20, ACR50 and ACR70 responses at week 24 (ITT population). Results demonstrate that treatment with tocilizumab is significantly better than treatment with methotrexate $\left({ }^{*} \mathrm{p}<0.001 ;{ }^{* *} \mathrm{p}=0.002\right.$; ${ }^{* *} \mathrm{p}<0.001$ ). (B) Proportion of methotrexate-naïve patients achieving ACR20, ACR50 and ACR70 responses at week 24 (ITT population); ${ }^{*}$ Weighted difference between groups $0.15(95 \% \mathrm{Cl} 0.05$ to 0.25$), \mathrm{p}<0.004 ;{ }^{*}$ *weighted difference between groups $0.14(95 \% \mathrm{Cl} 0.03$ to 0.24$), p=0.01$; $*_{* *}^{*}$ weighted difference between groups $0.15(95 \% \mathrm{Cl} 0.04$ to 0.25$), p=0.005$. (C) Time course for achievement of ACR20, ACR50 and ACR70 responses during 24 weeks of treatment with tocilizumab or methotrexate (ITT population). (D) Proportion of patients in clinical remission (DAS28 $<2.6$ ) and proportion of patients with good/moderate EULAR response at week 24 (ITT population). (E) CRP levels at each post-baseline visit during the 24-week study (ITT population); (F) Haemoglobin levels at each post-baseline visit during the 24-week study (safety population). CRP, C-reactive protein; DAS28, 28-joint Disease Activity Score; ITT, intention to treat; LLN, lower limit of normal; ULN, upper limit of normal.

Mean changes from baseline at week 24 in the ACR core parameters were consistently greater for tocilizumab than for methotrexate (table 2). A greater improvement in physical function was also reflected by the higher mean changes from baseline in HAQ-DI with tocilizumab.

Improvement in DAS28 at week 24 (ITT) was greater in the tocilizumab group than in the methotrexate group (adjusted mean change from baseline: -3.31 vs -2.05 ), and the proportion of patients in remission (DAS28 <2.6) at week 24 (ITT) was higher with tocilizumab than with methotrexate (fig 2D). By week 24, tocilizumab patients were five times more likely to achieve DAS28 remission (odds ratio vs methotrexate: 5.83; $95 \%$ CI 3.27 to 10.40 ), and approximately four times more likely to achieve at least a moderate EULAR response (odds ratio vs methotrexate: 4.24 , 95\% CI 2.92 to 6.14; fig 2D).

Notably, mean CRP levels were within the normal range as early as week 2 with tocilizumab, with persistently normal levels from weeks 12 to 24 in more than $90 \%$ of patients (fig $2 \mathrm{E}$, table 2). Furthermore, adjusted mean haemoglobin levels increased by $1.19 \mathrm{~g} / \mathrm{dl}$ from baseline in the tocilizumab group, and $0.10 \mathrm{~g} / \mathrm{dl}$ in the methotrexate group (ITT) by week 24. Improvement in haemoglobin levels was seen as early as week 2 (safety population; fig 2F) with normalisation of mean haemoglobin by week 6 in tocilizumab-treated patients with haemoglobin less than the lower limit of normal at baseline, an effect maintained through week 24 (13.4 g/dl; PP), not seen with methotrexate $(12.3 \mathrm{~g} / \mathrm{dl})$. 
Table 2 Mean changes from baseline in the ACR core set variables at week 24 (adjusted means; ITT population)

\begin{tabular}{|c|c|c|c|c|}
\hline ACR core set variables & $\begin{array}{l}\text { Tocilizumab } 8 \mathrm{mg} / \mathrm{kg} \\
(\mathrm{n}=286)\end{array}$ & $\begin{array}{l}\text { Methotrexate } \\
(\mathrm{n}=284)\end{array}$ & $\begin{array}{l}\text { Treatment difference } \\
(95 \% \mathrm{CI})\end{array}$ & $\begin{array}{l}\text { Superiority } \\
\text { criteria met }\end{array}$ \\
\hline SJC & -11.7 & -8.2 & $-3.5(-5.2$ to -1.7$)$ & Yes \\
\hline TJC & -17.2 & -13.9 & $-3.3(-5.9$ to -0.6$)$ & Yes \\
\hline Patient's global VAS (mm) & -34.5 & -30.7 & $-3.8(-8.9$ to 1.3$)$ & No \\
\hline Physician's global VAS (mm) & -41.3 & -31.7 & $-9.6(-13.5$ to -5.6$)$ & Yes \\
\hline Patient's pain VAS (mm) & -31.9 & -29.9 & $-2.0(-6.9$ to 3.0$)$ & No \\
\hline CRP (mg/dl) & -2.8 & -1.9 & $-0.9(-1.5$ to -0.3$)$ & Yes \\
\hline $\mathrm{ESR}(\mathrm{mm} / \mathrm{h})$ & -37.3 & -16.1 & $-21.1(-26.0$ to -16.2$)$ & Yes \\
\hline HAQ-DI & -0.7 & -0.5 & $-0.2(-0.3$ to -0.1$)$ & Yes \\
\hline
\end{tabular}

ACR, American College of Rheumatology; Cl, confidence interval; CRP, C-reactive protein; ESR, erythrocyte sedimentation rate; HAQ-DI, Health Assessment Questionnaire-Disability Index; ITT, intention to treat; SJC, swollen join count; TJC, tender joint count; VAS, visual analogue scale.

\section{Safety}

The overall incidence of AEs was similar in both groups $(79.9 \%$ tocilizumab vs $77.5 \%$ methotrexate; $p=0.484)$, as was the incidence of serious AEs (table 3). Most AEs were mild or moderate, with fewer than $7 \%$ of patients experiencing severe AEs.

The most common AEs during the study were infections (tocilizumab, 34.4\% vs methotrexate, 37.3\%; table 4). Infection rates per patient year were similar (tocilizumab, 1.06 vs methotrexate, 1.09). Skin and subcutaneous infections were reported with a higher frequency in the tocilizumab (4.1\%) than in the methotrexate group $(0.7 \%)$. The incidence of herpes infection was similar in the two treatment groups $(1.7 \%$ vs $1.4 \%)$. No fungal infections were reported in the tocilizumab group, but five patients $(1.8 \%)$ in the methotrexate group experienced fungal infection. No opportunistic infections were reported in this study. Serious infections were reported by four patients in the tocilizumab and two in the methotrexate group $(p=0.422$; table 4$)$.

The second most common AEs were gastrointestinal disorders, occurring with similar frequency in both groups. Five $(1.8 \%)$ patients in the methotrexate group and $1(0.3 \%)$ patient in the tocilizumab group were withdrawn from the study owing to gastrointestinal AEs.

Infusion reactions (any AE occurring during, or within $24 \mathrm{~h}$ after infusion) occurred in $5.6 \%$ of patients with tocilizumab and $1.8 \%$ with methotrexate $(p=0.016)$. The majority occurred during the first two infusions (tocilizumab: 10/16; methotrexate: $3 / 6$ ); no serious infusion reactions were reported.

Four patients died during the study: one in the methotrexate group (lung cancer), and three in the tocilizumab group (upper gastrointestinal haemorrhage/perforation (one), myocardial ischaemia (one) and cardiorespiratory arrest in a patient with history of asthma and arrhythmia (one)). The death due to gastrointestinal haemorrhage was considered by the investigator to be remotely related to treatment owing to short exposure to tocilizumab and the patient's medical history (peptic ulcer), although a relationship with treatment could not be excluded The other three deaths were deemed unrelated to the trial treatment.

More patients had reversible grade 3 neutropenia $(<1000$ 500 cells $/ \mathrm{mm}^{3}$ ) with tocilizumab, 3.1 versus methotrexate, $0.4 \%$ (fig 3A). One patient in the placebo/tocilizumab substudy arm discontinued owing to grade 4 neutropenia $\left(<500\right.$ cells $/ \mathrm{mm}^{3}$ ) and one patient owing to grade 3 neutropenia; both events resolved without sequelae. None of the patients with grade 3 or 4 neutropenia developed an infection or febrile neutropenia within the following month.

Fewer elevations in alanine and aspartate aminotransferase to $>3 \times$ the upper limit of normal (ULN) were seen with tocilizumab than with methotrexate (fig 3B). Three patients in the tocilizumab group compared with two in the methotrexate group discontinued the study treatment owing to aminotransferase elevations. Total bilirubin elevations (mostly indirect component) $>$ ULN and $<3 \times$ ULN were seen in 0.7 and $7.6 \%$ of patients in the methotrexate and tocilizumab groups, respectively, with no elevations seen concurrently with aminotransferase elevations. There were no clinical signs or symptoms of hepatitis or hepatic dysfunction.

Total cholesterol and low-density lipoprotein elevations were seen in more patients in the tocilizumab group than in the methotrexate group (fig 3C). No patients in either treatment group had changes in triglycerides from $<150 \mathrm{mg} / \mathrm{dl}$ to $\geqslant 500 \mathrm{mg} / \mathrm{dl}$. No clinical symptoms or cardiovascular events were reported in these patients.

\section{DISCUSSION}

These results demonstrate the superior efficacy of tocilizumab monotherapy over methotrexate monotherapy regardless of previous methotrexate exposure. Of note, at week 24, almost one-third of tocilizumab-treated patients achieved either DAS remission or an ACR70 in comparison with $12 \%$ and $15 \%$ of

Table 3 Cumulative adverse events to week 24 (safety population)

\begin{tabular}{lccl}
\hline Cumulative results for: & $\begin{array}{l}\text { Tocilizumab } \mathbf{8} \mathbf{~ m g / k g} \\
(\mathbf{n}=\mathbf{2 8 8})\end{array}$ & $\begin{array}{l}\text { Methotrexate } \\
(\mathbf{n}=\mathbf{2 8 4})\end{array}$ & $\mathbf{p}$ Value \\
\hline Any adverse event & $230(79.9)$ & $220(77.5)$ & 0.484 \\
Serious adverse event & $11(3.8)$ & $8(2.8)$ & 0.504 \\
$\quad$ Related serious adverse event & $4(1.4)$ & $4(1.4)$ & 0.984 \\
Adverse event leading to discontinuation & $11(3.8)$ & $15(5.3)$ & 0.401 \\
Adverse event leading to dose modification & $56(19.4)$ & $63(22.2)$ & 0.420 \\
Death & $3(1.0)$ & $1(0.4)$ & 0.322 \\
\hline
\end{tabular}

Results are shown an $\mathrm{n}(\%)$. 
Table 4 Most frequently reported adverse events (in $\geqslant 5 \%$ of patients)

\begin{tabular}{|c|c|c|c|}
\hline Adverse events & $\begin{array}{l}\text { Tocilizumab } 8 \mathrm{mg} / \mathrm{kg} \\
\text { (n=288) }\end{array}$ & $\begin{array}{l}\text { Methotrexate } \\
(\mathrm{n}=284)\end{array}$ & p Value \\
\hline Patients with at least one adverse event (total) & $230(79.9)$ & $220(77.5)$ & 0.484 \\
\hline Infections (total) & $99(34.4)$ & $106(37.3)$ & 0.462 \\
\hline Nasopharyngitis & $20(6.9)$ & $17(6.0)$ & \\
\hline Upper respiratory tract infection & $21(7.3)$ & $15(5.3)$ & \\
\hline Gastrointestinal disorders (total) & $86(29.9)$ & $89(31.3)$ & 0.702 \\
\hline Nausea & $18(6.3)$ & $34(12.0)$ & \\
\hline Diarrhoea & $15(5.2)$ & $15(5.3)$ & \\
\hline Investigations (total)* & $48(16.7)$ & $43(15.1)$ & 0.618 \\
\hline Skin and subcutaneous disorders (total) & $42(14.6)$ & $32(11.3)$ & 0.237 \\
\hline Musculoskeletal and connective tissue disorders (total) & $33(11.5)$ & $32(11.3)$ & 0.943 \\
\hline Nervous system disorders (total) & $37(12.8)$ & $18(6.3)$ & 0.008 \\
\hline Headache & $21(7.3)$ & $7(2.5)$ & \\
\hline General disorders and administration site conditions (total) & $21(7.3)$ & $24(8.5)$ & 0.607 \\
\hline Respiratory, thoracic and mediastinal disorders (total) & $26(9.0)$ & $19(6.7)$ & 0.299 \\
\hline Vascular disorders (total) & $24(8.3)$ & $13(4.6)$ & 0.068 \\
\hline Hypertension & $16(5.6)$ & $6(2.1)$ & \\
\hline Psychiatric disorders (total) & $20(6.9)$ & $11(3.9)$ & 0.105 \\
\hline Injury, poisoning and procedural complications (total) & $14(4.9)$ & $15(5.3)$ & 0.819 \\
\hline Eye disorders (total) & $15(5.2)$ & $9(3.2)$ & 0.224 \\
\hline \multicolumn{4}{|l|}{ Serious adverse events (in $\geqslant 3$ patients) } \\
\hline Total number of serious adverse events & 12 & 15 & \\
\hline Infections and infestations & $4(1.4)$ & $2(0.7)$ & \\
\hline Sepsis & - & $1(0.4)$ & \\
\hline Pneumonia & $2(0.7)$ & $1(0.4)$ & \\
\hline Sinusitis & $1(0.3)$ & - & \\
\hline Sialoadenitis & $1(0.3)$ & - & \\
\hline Injury, poisoning and procedural complications & $1(0.3)$ & $3(1.1)$ & \\
\hline Neoplasms benign, malignant and unspecified & $1(0.3)$ & $3(1.1)$ & \\
\hline
\end{tabular}

Results are shown as $\mathrm{n}(\%)$.

*Laboratory parameters.

methotrexate-treated patients, despite approximately twothirds of patients reaching and maintaining the $20 \mathrm{mg}$ methotrexate dose by week 8 . This outcome compares favourably with other trials comparing TNF antagonists with methotrexate using a similar dose titration. ${ }^{17-19}$ In the ERA trial, which enrolled patients with early RA, clinical endpoint results were similar for etanercept $25 \mathrm{mg}$ twice weekly and methotrexate $20 \mathrm{mg} /$ week at week 24, with DAS28 remission rates of $16 \%$ and $13 \%$, respectively. ${ }^{18}$ In TEMPO, where patients had a mean disease duration similar to patients in this study $(\sim 6.6$ years), but had received a mean of 2.3 prior DMARDs, ACR20/ $50 / 70$ responses were similar for etanercept and methotrexate (dosing similar to this study), with significance for etanercept superiority seen using the numeric ACRn response area under the curve. ${ }^{19}$ Lastly, in PREMIER, where patients had early RA, shorter disease duration ( $\sim 0.7$ years) and a comparable methotrexate dosing schedule, DAS28 remission rates at 12 months were $23 \%$ for adalimumab versus $21 \%$ for methotrexate monotherapy (not significant); however, a greater benefit could have been seen earlier in the treatment course. ${ }^{17}$

It is difficult to compare results across clinical trials owing to different patient populations with varying prior treatment and disease history. However, considering results of the above trials in the light of those from AMBITION, it appears that tocilizumab is the first biological agent to show statistically superior clinical efficacy using standard end points, compared with a standard methotrexate dose regimen in a 6-month study.

Efficacy was apparent as early as week 2 with tocilizumab and the rate and magnitude of clinically important improvements increased during the study. In addition, tocilizumab was associated with anaemia correction, commonly linked with RA, an effect not seen with methotrexate. ${ }^{23}$ Further, CRP and ESR decreased rapidly and substantially in the tocilizumab group, with mean CRP levels normalising by week 12 . Reduction in CRP may be associated with slowing of joint damage. ${ }^{24}{ }^{25}$ Combined with radiographic evidence from the SAMURAI study that tocilizumab, compared with DMARDs, inhibits progression of joint damage, the normalisation of CRP with tocilizumab monotherapy seen in AMBITION is encouraging. ${ }^{10}$

It is unlikely that prior experience with methotrexate significantly influenced results, as a similar proportion of patients in each treatment group (4\% in methotrexate group and 3\% in tocilizumab group) discontinued owing to AEs, and the reasons for discontinuation related to safety and refusal were comparable overall. To investigate this further, a post hoc analysis was conducted comparing pre-study methotrexate-naïve ( $\sim 66 \%$ ) with exposed $(\sim 34 \%)$ patients. Whereas patients exposed to methotrexate before AMBITION had longer mean disease duration (9 vs 5 years), received more DMARDs $(2.6$ vs $<1)$ and had higher use of corticosteroids ( $60 \%$ vs $40 \%$ ), the efficacy results were similar. Specifically, ACR20/50/70 for tocilizumab-treated patients was $73 \% / 42 \% / 30 \%$ (methotrexate-exposed) versus 69\%/45\%/27\% (methotrexate-naïve), and for methotrexate-treated patients were $50 \% / 34 \% / 17 \%$ and $54 \% / 33 \% / 14 \%$, respectively.

The overall incidence of AEs was similar between groups with a comparable incidence of serious AEs. As observed with other DMARD/biological agents, the most common AEs were infections. ${ }^{26-30}$ Although infections occurred with similar 

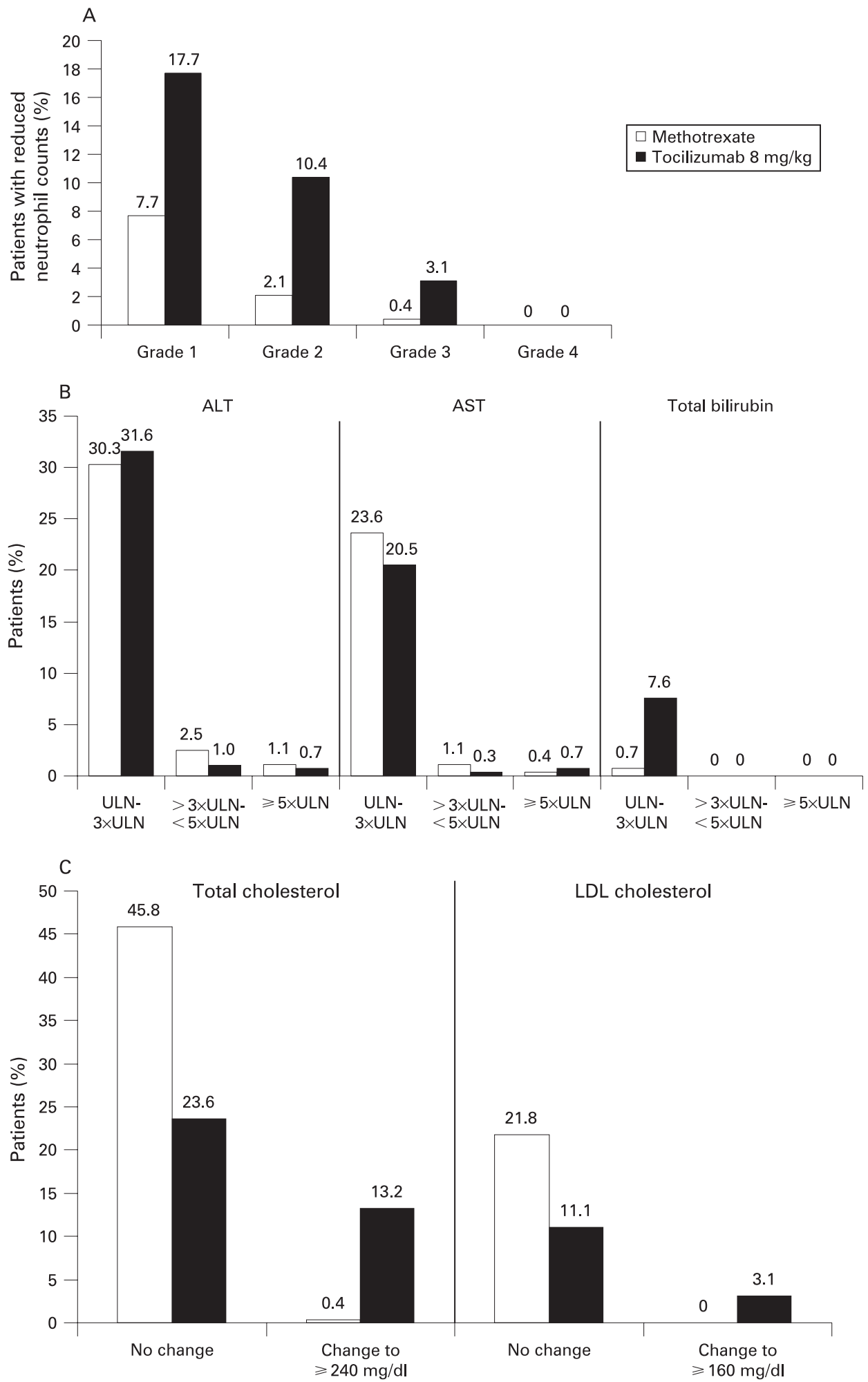

Figure 3 (A) Proportion of patients experiencing reduced neutrophil counts during the 24-week study (Safety population). (B) Patients with elevations in liver aminotransferases and total bilirubin levels from normal levels at baseline (AST $<40 \mathrm{U} / \mathrm{L}, \mathrm{ALT}<55 \mathrm{U} / \mathrm{L}$, total bilirubin $<17 \mu \mathrm{mol} / \mathrm{L}$; safety population). (C) Patients experiencing elevations in total and LDL cholesterol from $<200 \mathrm{mg} / \mathrm{dl}$ and $<100 \mathrm{mg} / \mathrm{dl}$ at baseline, respectively (Safety population). ALT, alanine aminotransferase; AST, aspartate aminotransferase; LDL, low-density lipoprotein; ULN, upper limit of normal.

incidence between the groups, serious/severe infections were twice as common with tocilizumab. The nature of serious infections was comparable considering the small numbers, as was the occurrence of herpes zoster. Interestingly, non-serious fungal skin infections occurred only in methotrexate-treated patients.
The other most common AEs were gastrointestinal disorders, with more patients discontinuing in the methotrexate group. Other AEs with an imbalance between the groups, included rash/ urticaria, headache, hypertension, which were more common in the tocilizumab group than in the methotrexate group. These events were typically mild, transient and not treatment limiting. 
Although the mechanism of action of tocilizumab is associated with a higher incidence of reversible reduction in neutrophil counts than methotrexate, there was no association with the occurrence or severity of infections in this study. However, given the potential for prolonged neutropenia to increase the risk of serious infections, this pharmacodynamic effect of IL6R inhibition requires periodic monitoring.

Increases in alanine aminotransferase (ALT)/aspartate aminotransferase (AST) occurred in both treatment groups, and were more common with methotrexate. In contrast, bilirubin elevations, without raised ALT/AST, were more common with tocilizumab, possibly a pharmacodynamic effect of hepatocyte IL6R inhibition. Modifications of dosing in response to ALT/ AST elevations as per-protocol, led to normalisation/improvement in the majority of patients, with more methotrexate patients (four) than tocilizumab patients (one) discontinuing owing to these elevations.

Increases in total cholesterol, low-density lipoprotein and high-density lipoprotein cholesterol were seen in more patients in the tocilizumab group than in the methotrexate group. These changes appeared to be associated with reduction in systemic inflammation, an effect also seen in patients treated with antiTNF biological agents. ${ }^{31-34}$ Although cardiovascular events were not seen in patients with these elevations during this study, treatment according to guidelines is recommended to deal with cardiovascular risk, and there remains a need for longer-term follow-up during chronic treatment to determine any implications of this effect.

In conclusion, the AMBITION study demonstrates that the efficacy of tocilizumab monotherapy in patients with relatively early active RA for whom methotrexate has not previously failed, is better than that of methotrexate monotherapy. Compared with methotrexate, tocilizumab monotherapy presents a unique safety profile for lipid elevations and reversible neutropenia associated with IL6R inhibition, the long-term significance of which remains to be determined. Nevertheless, the superior efficacy of tocilizumab in this study provides initial evidence of a benefit-risk that supports its use in patients with active moderate to severe RA.

Acknowledgements: We acknowledge the collaboration and commitment of all investigators and their staff, without whom this study would not have been possible. Editorial support was provided by Marcela Oancea, PhD from Phocus Services, in Basel, Switzerland, supported by F Hoffmann-La Roche Ltd.

Funding: This study was sponsored by F Hoffmann-La Roche Ltd.

Competing interests: GJ has received consulting fees from Merck, Roche, Genzyme, Novartis and Servier and has been paid lecture fees by Merck, Roche, Sanofi-Aventis, Servier, Pfizer and Novartis. ASe has received consulting fees from Amgen, Merck, Novartis and Roche, and has been paid lecture fees by Merck, Novartis, Roche, Glaxo Smith Kline and Lilly. AC has received lecture fees from Deutsche Pharma, Farmindustria, Schering Plough and Pfizer, has been paid lecture fees by Bristol-Myers Squibb and Merck, and has received grant support from Bristol-Myers Squibb, Merck and Roche. JJG-R has received consulting fees from Roche, Schering Plough, Wyeth and Bristol-Myers Squibb, and has been paid lecture fees by Roche, Wyeth and BristolMyers Squibb. ASi has received consulting fees from Roche. MT has received consulting fees from Roche and Schering Plough. TW and EA are employees of Roche. MCG has received consulting fees from Roche, Genentech, Biogen-Idec and BristolMyers Squibb, has been paid lecture fees by Genentech and Bristol-Myers Squibb and has received grant support from Roche, Genentech, Biogen-Idec, Bristol-Myers Squibb and Pfizer.

Ethics approval: Approved by institutional review boards/ethics committees.

Provenance and peer review: Not commissioned; externally peer reviewed.

Open Access This is an Open Access article distributed in accordance with the Creative Commons Attribution Non Commercial (CC BY-NC 3.0) license, which permits others to distribute, remix, adapt, build upon this work non-commercially, and license their derivative works on different terms, provided the original work is properly cited and the use is non-commercial. See: http://creativecommons.org/licenses/by-nc/3.0/

\section{REFERENCES}

1. Choy EH, Panayi GS. Cytokine pathways and joint inflammation in rheumatoid arthritis. N Engl J Med 2001;344:907-16.

2. Kishimoto T. Interleukin-6: discovery of a pleiotropic cytokine. Arthritis Res Ther 2006;8(Suppl 2):S2

3. Tamura T, Udagawa N, Takahashi N, Miyaura C, Tanaka S, Yamada Y, et al. Soluble interleukin-6 receptor triggers osteoclast formation by interleukin 6. Proc Natl Acad Sci USA 1993:90:11924-8.

4. Sack U, Kinne RW, Marx T, Heppt P, Bender S, Emmrich F. Interleukin-6 in synovial fluid is closely associated with chronic synovitis in rheumatoid arthritis. Rheumatol Int 1993:13:45-51.

5. Madhok R, Crilly A, Watson J, Capell HA. Serum interleukin 6 levels in rheumatoid arthritis: correlations with clinical and laboratory indices of disease activity. Ann Rheum Dis 1993;52:232-4

6. Hirano T. Interleukin 6 and its receptor: ten years later. Int Rev Immunol 1998;16:249-84.

7. Rose-John S, Waetzig GH, Scheller J, Grotzinger J, Seegert D. The IL-6/sIL-6R complex as a novel target for therapeutic approaches. Expert Opin Ther Targets 2007;11:613-24

8. Maini RN, Taylor PC, Szechinski J, Pavelka K, Broll J, Balint G, et al. Double-blind randomized controlled clinical trial of the interleukin-6 receptor antagonist, tocilizumab, in European patients with rheumatoid arthritis who had an incomplete response to methotrexate. Arthritis Rheum 2006;54:2817-29.

9. Nishimoto N, Yoshizaki K, Miyasaka N, Yamamoto K, Kawai S, Takeuchi T, et al. Treatment of rheumatoid arthritis with humanized anti-interleukin-6 receptor antibody: a multicenter, double-blind, placebo-controlled trial. Arthritis Rheum 2004:50:1761-9.

10. Nishimoto N, Hashimoto J, Miyasaka N, Yamamoto K, Kawai S, Takeuchi T, et al. Study of active controlled monotherapy used for rheumatoid arthritis, an IL-6 inhibitor (SAMURAI): - evidence of clinical and radiographic benefit from an $x$-ray readerblinded randomized controlled trial of tocilizumab. Ann Rheum Dis 2007:66:1162-7.

11. Genovese MC, McKay JD, Nasonov EL, Mysler EF, da Silva NA, Alecock E, et al Interleukin-6 receptor inhibition with tocilizumab reduces disease activity in rheumatoid arthritis with inadequate response to disease-modifying antirheumatic drugs: The tocilizumab in combination with traditional disease-modifying antirheumatic drug therapy study. Arthritis Rheum 2008;58:2968-80.

12. Smolen JS, Beaulieu A, Rubbert-Roth A, Ramos-Remus C, Rovensky J, Alecock E, et al. Effect of interleukin-6 receptor inhibition with tocilizumab in patients with rheumatoid arthritis (OPTION study): a double-blind, placebo-controlled, randomised trial. Lancet 2008:371:987-97.

13. Emery P, Keystone E, Tony HP, Cantagrel A, van Vollenhoven R, Sanchez A, et al. IL6 receptor inhibition with tocilizumab improves treatment outcomes in patients with rheumatoid arthritis refractory to anti-tumour necrosis factor biologicals: results from a 24-week multicentre randomised placebo-controlled trial. Ann Rheum Dis 2008;67:1516-23.

14. American College of Rheumatology Subcommittee on Rheumatoid Arthritis Guidelines. Guidelines for the management of rheumatoid arthritis: 2002 update. Arthritis Rheum 2002:46:328-46.

15. Gaffo A, Saag KG, Curtis JR. Treatment of rheumatoid arthritis. Am J Health Syst Pharm 2006;63:2451-65.

16. Jones G, Halbert J, Crotty M, Shanahan EM, Batterham M, Ahern M. The effect of treatment on radiological progression in rheumatoid arthritis: a systematic review of randomized placebo-controlled trials. Rheumatology (Oxford) 2003:42:6-13.

17. Breedveld FC, Weisman MH, Kavanaugh AF, Cohen SB, Pavelka K, van Vollenhoven $\mathrm{R}$, et al. The PREMIER study: A multicenter, randomized, double-blind clinical trial of combination therapy with adalimumab plus methotrexate versus methotrexate alone or adalimumab alone in patients with early, aggressive rheumatoid arthritis who had not had previous methotrexate treatment. Arthritis Rheum 2006:54:26-37.

18. Bathon JM, Martin RW, Fleischmann RM, Tesser JR, Schiff MH, Keystone EC, et al A comparison of etanercept and methotrexate in patients with early rheumatoid arthritis. N Engl J Med 2000;343:1586-93.

19. Klareskog L, van der Heijde D, de Jager JP, Gough A, Kalden J, Malaise M, et al Therapeutic effect of the combination of etanercept and methotrexate compared with each treatment alone in patients with rheumatoid arthritis: double-blind randomised controlled trial. Lancet 2004;363:675-81.

20. Felson DT, Anderson JJ, Boers M, Bombardier C. Furst D, Goldsmith C, et al. American College of Rheumatology. Preliminary definition of improvement in rheumatoid arthritis. Arthritis Rheum 1995;38:727-35.

21. Fransen J, van Riel PL. The Disease Activity Score and the EULAR response criteria Clin Exp Rheumatol 2005;23:S93-9.

22. Prevoo ML, van 't Hof MA, Kuper HH, van Leeuwen MA, van de Putte LB, van Riel PL. Modified disease activity scores that include twenty-eight-joint counts Development and validation in a prospective longitudinal study of patients with rheumatoid arthritis. Arthritis Rheum 1995:38:44-8.

23. Wolfe F, Michaud K. Anemia and renal function in patients with rheumatoid arthritis. $J$ Rheumatol 2006;33:1516-22.

24. Emery P, Gabay C, Kraan M, Gomez-Reino J. Evidence-based review of biologic markers as indicators of disease progression and remission in rheumatoid arthritis Rheumatol Int 2007:27:793-806.

25. Scott DL. Radiological progression in established rheumatoid arthritis. J Rheumatol Supp/ 2004;31:55-65. 
26. Keystone EC, Kavanaugh AF, Sharp JT, Tannenbaum H, Hua Y, Teoh LS, et al. Radiographic, clinical, and functional outcomes of treatment with adalimumab (a human anti-tumor necrosis factor monoclonal antibody) in patients with active rheumatoid arthritis receiving concomitant methotrexate therapy: a randomized, placebo-controlled, 52-week trial. Arthritis Rheum 2004;50:1400-11.

27. Kremer JM, Genant HK, Moreland LW, Russell AS, Emery P, Abud-Mendoza C, et al. Effects of abatacept in patients with methotrexate-resistant active rheumatoid arthritis: a randomized trial. Ann Intern Med 2006;144:865-76.

28. Maini R, St Clair EW, Breedveld F, Furst D, Kalden J, Weisman M, et al. Infliximab (chimeric anti-tumour necrosis factor alpha monoclonal antibody) versus placebo in rheumatoid arthritis patients receiving concomitant methotrexate: a randomised phase III trial. ATTRACT Study Group. Lancet 1999;354:1932-9.

29. van der Veen MJ, van der Heide A, Kruize AA, Bijlsma JW. Infection rate and use of antibiotics in patients with rheumatoid arthritis treated with methotrexate. Ann Rheum Dis 1994;53:224-8.
30. Bernatsky S, Hudson M, Suissa S. Anti-rheumatic drug use and risk of serious infections in rheumatoid arthritis. Rheumatology (Oxford) 2007;46:1157-60.

31. Seriolo B, Paolino S, Sulli A, Fasciolo D, Cutolo M. Effects of anti-TNF-alpha treatment on lipid profile in patients with active rheumatoid arthritis. Ann N Y Acad Sci 2006;1069:414-9.

32. Tam LS, Tomlinson B, Chu TT, Li TK, Li EK. Impact of TNF inhibition on insulin resistance and lipids levels in patients with rheumatoid arthritis. Clin Rheumatol 2007;26:1495-8.

33. Vis M, Nurmohamed MT, Wolbink G, Voskuyl AE, de Koning M, van de Stadt R, et al. Short term effects of infliximab on the lipid profile in patients with rheumatoid arthritis. J Rheumatol 2005;32:252-5.

34. Sattar N, McCarey DW, Capell H, McInnes IB. Explaining how "high-grade" systemic inflammation accelerates vascular risk in rheumatoid arthritis. Circulation 2003;108:2957-63. 